УДК 368.5

$10.17213 / 2075-2067-2020-4-98-104$

\title{
ОСОБЕННОСТИ СТРАХОВАНИЯ В АГРАРНОЙ СФЕРЕ РОССИИ
}

\author{
(C) 2020 г. Е. Г. Мещцанинова
}

\section{Новочеркасский инженерно-мелиоративный институт имени А. К. Кортунова (филиал), Донской государственный аграрный университет, 2. Новочеркасск, Россия}

Целью исследования является анализ и обоснование особенностей страхования одной из крупных отраслей экономики России - сельского хозяйства, обусловленные природньми, климатическими и почвенными условиями.

Методологической основой исследования являются работы отечественных ученыхэкономистов, посвященные проблемам страхования, рассматривающие агрострахование как один из инструментов устойчивого развития экономики России. Исследование базируется также на монографическом методе исследования и SWOT-анализе отрасли агрострахования. Несмотря на то, что методологические основы страхования имеют значительную историю, однако недостаточно полно исследованы проблемы внедрения более гибких инструментов агрострахования.

Результаты исследования. Сущность агрострахования в современных условиях заключается в обеспечении защиты агропроизводителей в случае наступления страховых рисков. Однако, проведенный SWOT-анализ отрасли позволяет сделать вывод о низкой мотивачии агрострахования и недостаточном доверии со стороны агропроизводителей.

Перспективу исследования составляет дальнейший анализ и изучение возможности применения данных дистанщионного зондирования в качестве доказательной базы при наступлении страховых случаев в сельскохозяйственном производстве.

Ключевые слова: сельское хозяйство; агрострахование; застрахованная площадь; сельскохозяйственное производство.

\section{FEATURES OF INSURANCE IN THE AGRICULTURAL SECTOR OF RUSSIA}

\section{(C) 2020 E. G. Meshchaninova}

\section{Novocherkassk Reclamation Engineering Institute named after A. K. Kortunov (branch), Donskoy State Agrarian University, Novocherkassk, Russia}

The purpose of the study is to analyze and substantiate the features of insurance of one of the major branches of the Russian economy - agriculture, due to natural, climatic and soil conditions.

The methodological basis of the research is the work of Russian scientists and economists devoted to the problems of insurance, considering agricultural insurance as one of the tools for sustainable development of the Russian economy. The research is also based on the monographic research method and SWOT analysis of the agricultural insurance industry. Despite the fact that the methodological foundations of insurance have a significant history, however, the problems of introducing more flexible agricultural insurance tools have not been fully investigated. 
Research result. The essence of agricultural insurance in modern conditions is to ensure the protection of agricultural producers in the event of insurance risks. However, the SWOT analysis of the industry allows us to conclude that there is low motivation for agricultural insurance and insufficient confidence on the part of agricultural producers.

The research perspective is further analysis and study of the possibility of using remote sensing data as an evidence base for the occurrence of insurance events in agricultural production.

Key word: agriculture; agricultural insurance; insured area; agricultural production.

Введение. Сельское хозяйство - крупная отрасль экономики России. Объём сельскохозяйственного производства в России в 2019 году составил около 5,9 трлн. руб. Ведущей отраслью является растениеводство, на которое приходится $54 \%$ объёма сельскохозяйственного производства, доля животноводства - $46 \%$ [1]. Это обусловлено тем, что Россия занимает одно из ведущих мест в мире по площади почв, пригодных для земледелия [5]. Развитие отрасли агрострахования может внести весомый вклад в стратегию устойчивого развития сельского хозяйства России [8].

Несмотря на значительные площади земель, занятых в сельскохозяйственном производстве, $64 \%$ из них находятся в зоне рискованного земледелия, поэтому сельскохозяйственное страхование от опасных природных гидрометеорологических явлений (засуха, заморозки, град и т.д.) должно иметь исключительное значение для устойчивого развития АПК [6]. Исходя из этого, можно было бы предположить, что в нашей стране широко развито агрострахование, однако, в 2017 г. в России было застраховано только 1,7\% площади посевов (рисунок 1).

Основные конкуренты России на мировом рынке аграрной продукции активно развивают агрострахование. Охват страхованием развитых стран, занимающихся производством сельскохозяйственной продукции, составляет от 30 до 90\% площади посевов. В частности, в США и Канаде - $85 \%$, Испании и Германии - $60 \%$, Франции - 55\%, ЮАР - 40\%, Китае - 35\%, Индии - 30\% посевов застрахованы.

Наряду с неблагоприятными природными явлениями, существеннейший урон урожаю сельскохозяйственной продукции наносят чрезвычайные ситуации. Ущерб от засухи в 2010 г. превысил 42 млрд. руб., засуха в Сибири в 2012 г. — ущерб в 14 млрд. руб., навод-

\section{Объем продукции (пшеница), млн тонн (2017/2018)}

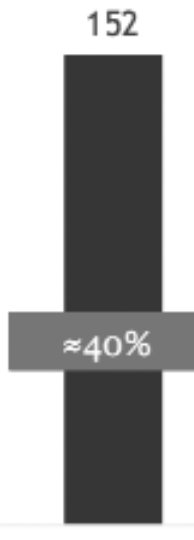

1. EC
2. Китай

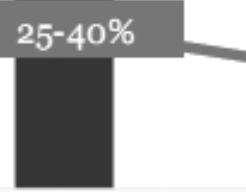

Охват посевов агрострахованием, \%

Рис. 1. Российский АПК на международном рынке [2] 


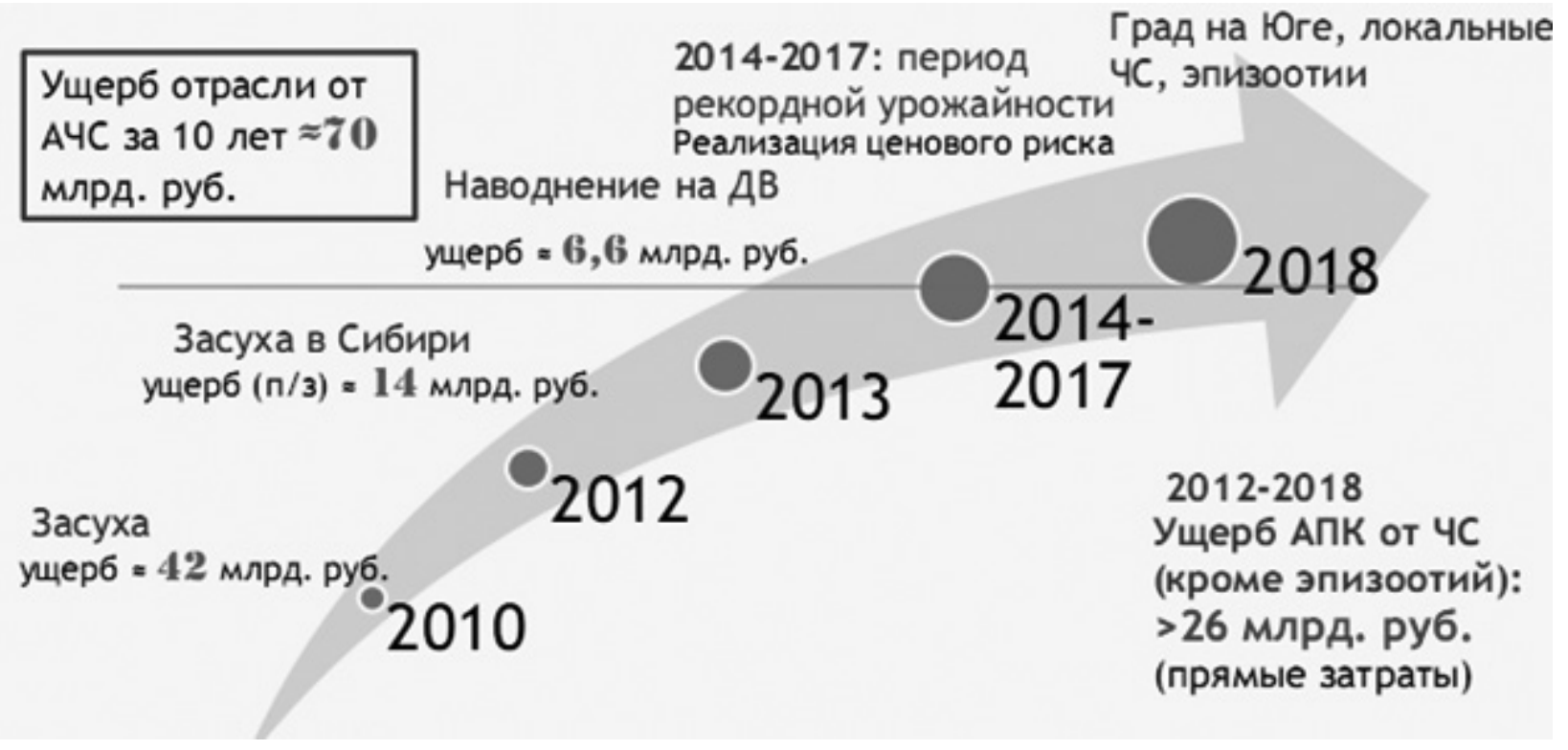

Рис. 2. Реализация крупных рисков в АПК РФ с 2010 г. [3]

нение на Дальнем Востоке, град на юге России, а также ежегодные чрезвычайные ситуации локального характера в субъектах РФ нанесли ущерб АПК более чем на 26 млрд. руб. (рисунок 2).

Современное состояние и тенденции развития страхования в аграрной сфере. В 2019 году объем застрахованных площадей в России составил 4,3 млн. га, или $6 \%$ от всей посевной площади, что в 3,2 раза выше по сравнению с 2018 годом. Что касается животноводства, то в 2019 году было застраховано 6,3 млн. условных голов, или 21,9\% от всего поголовья сельскохозяйственных животных в стране. Это в 1,3 раза выше показателя 2018 года, когда было застраховано 4,8 млн. условных голов, или $16,7 \%$ всего поголовья в стране.

Таблица 1

ТОП-10 лидирующих регионов РФ по объему субсидируемого агрострахования, І полугодие 2019 года [4]

\begin{tabular}{|c|l|c|c|c|}
\hline \multirow{2}{*}{ № } & \multirow{2}{*}{ Регион } & \multicolumn{3}{c|}{$\begin{array}{r}\text { Сумма начисленной страховой премии, млн. руб., } \\
\text { по страхованию с господдержкой }\end{array}$} \\
\cline { 3 - 5 } & & Всего & с/х культур & c/х животных \\
\hline 1 & Воронежская область & 368 & 286,8 & 81,1 \\
\hline 2 & Самарская область & 241,9 & 231,4 & 10,5 \\
\hline 3 & Республика Татарстан & 158,6 & 149,4 & 9,2 \\
\hline 4 & Республика Мордовия & 145,8 & 145,5 & 0,3 \\
\hline 5 & Орловская область & 140,1 & 99,6 & 40,4 \\
\hline 6 & Краснодарский край & 111,8 & 105,3 & 6,4 \\
\hline 7 & Белгородская область & 66,4 & 17,6 & 48,7 \\
\hline 8 & Алтайский край & 59,5 & 54,1 & 5,4 \\
\hline 9 & Калининградская область & 54,1 & 0 & 54,1 \\
\hline 10 & Липецкая область & 53 & 9 & 43,9 \\
\hline Всего ТОП-10 & 1399 & 1099 & 300 \\
\hline
\end{tabular}




\section{SWOT-анализ отрасли агрострахования}

\begin{tabular}{|c|c|}
\hline Іьные с & W (слабые стороны) \\
\hline $\begin{array}{l}\text { - расширение предела допустимых страховых сумм - } \\
\text { возможность страхования на страховую сумму в пределах } \\
\text { от } 70 \text { до } 100 \% \text { от страховой стоимости (ранее - от } 80 \text { до } \\
100 \%) ; \\
\text { - отказ от порогового уровня гибели урожая или насажде- } \\
\text { ний для признания убытка страховым событием (ранее - } \\
20 \% \text { урожая по сравнению с запланированным или гибель } \\
\text { многолетних насаждений не менее чем на } 30 \% \text { площади); } \\
\text { - замена условной франшизы в размере } 20 \% \text { на безуслов- } \\
\text { ную в размере не менее чем } 10 \% \text { от страховой суммы (для } \\
\text { рисков растениеводства); } \\
\text { - расширение коридора для допустимой безусловной } \\
\text { франшизы - возможно ее установление в пределах от } \\
10 \% \text { до 50\% от страховой суммы (ранее - от } 0 \text { до } 30 \%) ; \\
\text { - расширение перечня рисков, подлежащих страхованию; } \\
\text { - возможность выбора одного или нескольких рисков для } \\
\text { целей страхования; } \\
\text { - ограничение территории страхования по одному поли- } \\
\text { су пределами одного субъекта РФ; } \\
- \text { предоставление возможности сострахования одного } \\
\text { крупного объекта несколькими страховщиками; } \\
\text { - закрепление правового статуса методов космической и } \\
\text { аэрофотосъемки для целей страховой экспертизы. }\end{array}$ & $\begin{array}{l}\text { - недостаточное доверие к рын- } \\
\text { ку страхования; } \\
\text { - отсутствие разработки допол- } \\
\text { нительных программ страхова- } \\
\text { ния в рамках действующей сис- } \\
\text { темы; } \\
\text { - недостаточный охват малого } \\
\text { и среднего бизнеса с использо- } \\
\text { ванием инновационных методов; } \\
\text { - недостаточная информиро- } \\
\text { ванность органов АПК по вопро- } \\
\text { сам развития агрострахования; } \\
\text { - отсутствие дополнительных } \\
\text { условий для регионов с систем- } \\
\text { ными рисками; } \\
\text { - необоснованные отказы в за- } \\
\text { ключении договоров или зани- } \\
\text { жение страховых выплат со сто- } \\
\text { роны страховых организаций; } \\
\text { - низкая мотивация агрострахо- } \\
\text { вания }\end{array}$ \\
\hline (D) & \\
\hline $\begin{array}{l}\text { - субсидирование большего количества договоров аг- } \\
\text { рострахования в рамках располагаемых лимитов финан- } \\
\text { сирования за счет расширенного диапазона доступных } \\
\text { франшиз и страховых сумм; } \\
\text { г внесение изменений в Госпрограмму развития сельско- } \\
\text { го хозяйства с выделением мер по управлению рисками, } \\
\text { включая страхование; } \\
\text { - переход к планированию мер по управлению рисками } \\
\text { на уровне органов АПК субъектов РФ; } \\
\text { - учет наличия страховой защиты при предоставлении } \\
\text { господдержки на реализацию крупных инвестиционных } \\
\text { проектов в отрасли АПК или проектов по развитию отде- } \\
\text { льных направлений агропроизводства, в т.ч. в животно- } \\
\text { водстве, садоводстве, виноградарстве; } \\
\text { - дополнительная адаптация условий страхования к спе- } \\
\text { цифике отдельных направлений агропроизводства; } \\
\text { - расширение охвата страхованием малого и среднего } \\
\text { бизнеса, в т.ч. за счет внедрения инновационных методов } \\
\text { страхования; } \\
\text { - повышение уровня владения страховыми инструмента- } \\
\text { ми в среде сельхозпроизводителей }\end{array}$ & $\begin{array}{l}\text { — высокая убыточность из-за } \\
\text { погодных рисков; } \\
\text { - изменение страхового законо- } \\
\text { дательства; } \\
\text { - низкая платежеспособность } \\
\text { сельхозтоваропроизводителей; } \\
\text { - рост тарифов на агрострахо- } \\
\text { вание; } \\
\text { - проблематичность для сель- } \\
\text { хозтоваропроизводителей в пре- } \\
\text { доставлении доказательств о } \\
\text { соблюдении всех условий агро- } \\
\text { техники; } \\
\text { - страховое мошенничество }\end{array}$ \\
\hline
\end{tabular}


В 2020 году страховые компании союза НСА готовы застраховать урожай и поголовье не менее чем в 68 регионах России, при этом может быть застраховано не менее 7,8 млн. га.

«Восстановление практики господдержки агрострахования, которое наблюдается в 2019 году, вновь вывело на первые позиции в рейтинге по объемам рынка крупнейшие аграрные регионы России, среди которых более трети - субъекты Юга России», - отметил президент НСА Корней Биждов [4] (таблица 1).

Несмотря на выросший объем рынка агрострахования, в 2019 году ущерб АПК от последствий ЧС природного характера составил порядка 13,2 млрд. рублей, это превышает ущерб отрасли от природных явлений за три предыдущих года (сильные дожди, наводнения, крупные лесные пожары). «Развитие агрострахования в России пока находится на недостаточном уровне для полноценной защиты АПК от рисков чрезвычайных бедствий» отметил президент НСА [7].

Несмотря на восстановление практики агрострахования, предполагаемый объем застрахованных площадей в России не превысит в 2020 году $12 \%$ от всей посевной площади. Проведем SWOT-анализ отрасли агрострахования (таблица 2).

Заключение. Как видно из анализа, основными причинами низкого объёма агрострахования со стороны агропроизводителей являются: недостаточная информированность и недоверие к рынку страхования, а также низкая мотивация агрострахования. Со стороны отрасли недостатком является её непроработанность и незавершенность.

Динамичное участие НСA в развитии отрасли агрострахования при активном участии государства должно привести не только к инвестиционной привлекательности агрострахования и увеличению охвата страхования до 40-60\% посевов, что сопоставимо с зарубежными странами, но и к устойчивому развитию сельского хозяйства.

\section{Литература}

1. Сельское хозяйство в России [Электронный ресурс]. - Режим доступа: https:// ru.wikipedia.org/wiki/Сельское_хозяйство_ России.
2. Борануков М. Совершенствование системы государственной поддержки агрострахования // Министерская научная дискуссия на тему «Повышение эффективности бюджетной политики и оптимизации бюджетных расходов на развитие отраслей АПК с учетом опыта государственной поддержки сельского хозяйства в зарубежных странах» [Электронный ресурс]. - Режим доступа: https://nifi.ru/ images/FILES/NEWS/2018/Boranykov.

3. Борануков M. Организация агрострахования с государственной поддержкой в 2019 году с учетом изменений законодательства // Семинар «Управление рисками в аграрном производстве» [Электронный ресурс]. Режим доступа: //docviewer.yandex.ru.

4. ТОП-10 регионов РФ по объему агрострахования [Электронный ресурс]. - Режим доступа: http://www.insur-info.ru/about_ $\mathrm{mig} / \mathrm{rules} /$.

5. Соломкина Л. Г. Землепользование и аграрные преобразования // Экономика сельского хозяйства России. - 2001. — №3. - С. 30.

6. Мещзанинова Е.Г. Агрострахование в России: проблемы и инструменты // В сборнике: Актуальные проблемы и перспективы развития экономики Труды XVIII Всероссийской с международным участием научнопрактической конференции. Под редакцией Н. В. Апатовой. - 2019. - С. 179-180.

7. Объем рынка агрострахования в 2019 г. превысил 5,3 млрд. рублей // Агроинвест [Электронный журнал]. - Режим доступа: https://agrovesti.net/about.html.

8. Ткачева О.А., Мещанинова Е.Г. Эколого-экономические аспекты устойчивости сельскохозяйственного землепользования// В сборнике: Новые методы и результаты исследований ландшафтов в Европе, Центральной Азии и Сибири: Монография. В 5 томах. - Москва, 2018. - С. 61-64.

\section{References}

1. Sel'skoe hozjajstvo v Rossii [Agriculture in Russia] [Jelektronnyj resurs]. — URL: https:// ru.wikipedia.org/wiki/Сельское_хозяйство_ России.

2. Boranukov M. Sovershenstvovanie sistemy gosudarstvennoj podderzhki agrostrahovanija [Improving the system of state support for agricultural insurance] // Ministerskaja nauchnaja 
diskussija na temu «Povyshenie jeffektivnosti bjudzhetnoj politiki i optimizacii bjudzhetnyh rashodov na razvitie otraslej APK $\mathrm{s}$ uchetom opyta gosudarstvennoj podderzhki sel'skogo hozjajstva v zarubezhnyh stranah» [Ministerial scientific discussion on "Improving the effectiveness of budget policy and optimizing budget expenditures for the development of agricultural industries, taking into account the experience of state support for agriculture in foreign countries»] [Jelektronnyj resurs]. — URL: https:// nifi.ru/images/FILES/NEWS/2018/Boranykov.

3. Boranukov $M$. Organizacija agrostrahovanija s gosudarstvennoj podderzhkoj v 2019 godu s uchetom izmenenij zakonodatel'stva [Organization of agricultural insurance with state support in 2019, taking into account changes in legislation] // Seminar "Upravlenie riskami v agrarnom proizvodstve» [Seminar «Risk Management in agricultural production»] [Jelektronnyj resurs]. — URL: //docviewer.yandex.ru.

4. TOP-10 regionov RF po obemu agrostrahovanija [TOP 10 regions of the Russian Federation in terms of agricultural insurance] [Jelektronnyj resurs]. — URL: http://www.insur-info. ru/about mig/rules/.

5. Solomkina L.G. Zemlepol'zovanie i agrarnye preobrazovanija [Land use and agricultural transformation] // Jekonomika sel'skogo hozjajstva Rossii [Economics of agriculture of Russia]. - 2001. — №3. - P. 30.

6. Meshhaninova E.G. Agrostrahovanie v Rossii:problemy i instrumenty [Agricultural insurance in Russia: problems and tools] // V sbornike: Aktual'nye problemy i perspektivy razvitija jekonomiki Trudy XVIII Vserossijskoj s mezhdunarodnym uchastiem nauchno-prakticheskoj konferencii. Pod redakciej N.V. Apatovoj [In the collection: Actual problems and prospects of economic development Proceedings of the XVIII all-Russian scientific and practical conference with international participation. In N. V. Apatova (eds.)]. - 2019. — Pp. 179-180.

7. Obem rynka agrostrahovanija v $2019 \mathrm{~g}$. prevysil 5,3 mlrd rublej [The volume of the agricultural insurance market in 2019 exceeded 5.3 billion rubles] // Agroinvest [Jelektronnyj zhurnal]. — URL: https://agrovesti.net/about.html.

8. Tkacheva O.A., MeshhaninovaE.G. Jekologo-jekonomicheskie aspekty ustojchivosti sel'skohozjajstvennogo zemlepol'zovanija [Ecological and economic aspects of sustainable agricultural land use] // V sbornike: Novye metody i rezul'taty issledovanij landshaftov v Evrope, Central'noj Azii i Sibiri: Monografija. V 5 tomah [In the collection: New methods and results of landscape research in Europe, Central Asia and Siberia: Monograph. In 5 volumes]. - Moscow, 2018. - Pp. 61-64. 


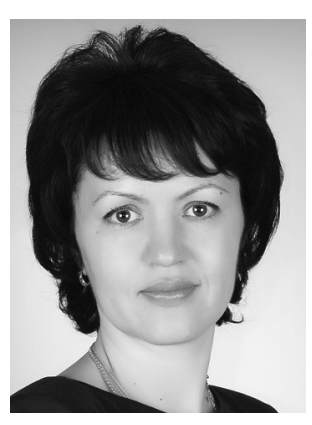

Мещанинова Елена Германовна - кандидат экономических наук, доцент кафедры «Кадастр и мониторинг земель» Новочеркасского инженерно-мелиоративного института имени А. К. Кортунова (филиала) Донского государственного аграрного университета. Является автором работ по эколого-экономической оценке природопользования, рациональному аграрному природопользованию.

Meshchaninova Elena Germanovna - Candidate of Economic Sciences, Associate Professor of the Department of Cadastre and Land Monitoring, Novocherkassk Reclamation Engineering Institute named after A. K. Kortunov (branch), Donskoy State Agrarian University. She is the author of works on environmental and economic assessment of nature management, rational agricultural nature management.

346400, г. Новочеркасск, ул. Пушкинская, 111

111 Pushkinskaya st., 346400, Novocherkassk, Russia

Email: forpost-MEG@yandex.ru 